\title{
MUSEO DE VOLCANES NOCHEBUENA, VOLCÁN IRAZÚ, COSTA RICA
}

\author{
NOCHEBUENA VOLCANO MUSEUM, IRAZÚ VOLCANO, COSTA RICA
}

\author{
Federico Gutiérrez
}

\section{Complejo Turístico Nochebuena, Apartado 140-1225, Costa Rica volcanirazu@me.com; gutierrezberry@gmail.com}

(Recibido: 9/5/2012; aceptado: 11/6/2013)

\begin{abstract}
The Nochebuena Volcano Museum, located $5 \mathrm{~km}$ before the main entrance of the Irazú Volcano National Park, is the only private museum in Costa Rica, created in 2008, focus on the education about the volcanoes and natural resources.

Keywords: Nochebuena Museum, Irazú, Costa Rica

RESUMEN: E1 Museo Volcanes Nochebuena, ubicado a $5 \mathrm{~km}$ antes de la entrada al Parque Nacional Volcán Irazú, es el único museo privado, creado en el 2008, dedicado a la educación de los volcanes y los recursos naturales.

Palabras clave: Museo de Volcanes Nochebuena, Irazú, Costa Rica
\end{abstract}


El recorrido comienza en una sala de proyección de películas, en la cual se presenta un video relacionado con los fenómenos volcánicos y, en especial, con el volcán Irazú, dando énfasis en la actividad de 1963. En esta sala también se pueden apreciar fotografías del Irazú en diferentes periodos. Continuando el recorrido, se encuentran leyendas relacionadas con volcanes, como la de Vulcano (el Dios del fuego), Iztarú, Atlántida o la del Popocatepetl. En una sala contigua, se explica la formación de los volcanes y su interacción con las capas de la Tierra, así como las partes de un volcán. Un panel iluminado muestra los volcanes más importantes de la Tierra y de otros planetas como Marte, Saturno y Júpiter. Más adelante, se encuentra un mapa en relieve de la topografía de Costa Rica, en donde se iluminan los volcanes más importantes y sus características principales. Después aparece una fotografía aérea de la zona de los cráteres con una explicación sobre estos y los puntos más importantes de esta zona. En una pared de esta sala, se observan recortes de periódicos que hacen referencia a la actividad del volcán Irazú en 1963; además, es posible observar una muestra de la ceniza de esa época. En otra sala se exponen las características naturales de la zona con su fauna principal, expuestos en forma disecada, así como una explicación sobre la hidrografía y agricultura del lugar y sobre la vida cotidiana de sus habitantes. Una maqueta en movimiento hace hincapié en la riqueza hídrica del volcán Irazú y la forma en que el ser humano ha utilizado esa energía para su beneficio. Uno de los puntos más entretenidos es la sala de juegos, en donde se pueden resolver los acertijos y manualidades en la sala de juegos.

El Museo recibe la visita de cientos de turistas nacionales e internacionales que han escrito,
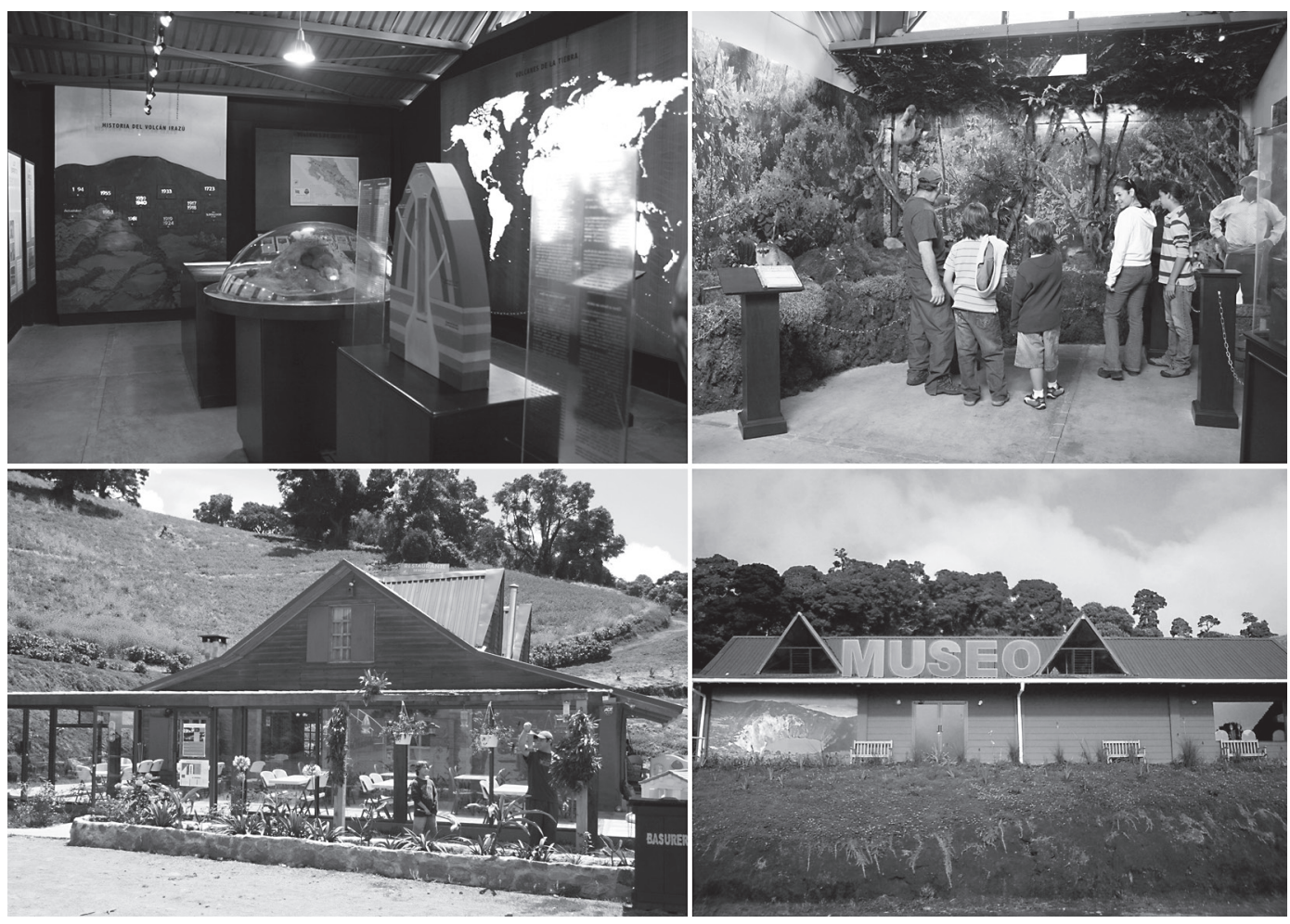

Fig. 1: Diferentes tomas de las instalaciones del Museo de volcanes Nochebuena y el complejo turístico del mismo nombre. 
en el libro de registro, conmovedores comentarios sobre su calidad. Además, continuamente recibe grupos de estudiantes de todos los niveles de primaria, secundaria y universitarios. El museo Nochebuena, junto con otros museos nacionales e internacionales que poseen salas (permanentes o temporales) destinadas a procesos ígneos (volcanes, rocas ígneas y geotermia), constribuyen a la educación y al geoturismo (ver p.e. Bundschuch et al., 2007). Para más información, consultar http://www.nochebuena.org

\section{AGRADECIMIENTOS}

Eugenia Zavaleta y Guillermo Alvarado se tomaron la molestia de revisar la presente nota.

\section{REFERENCIAS}

ALVARADO, G.E., 2009: Los volcanes de Costa Rica: Geología, historia, riqueza natural y su gente. -xxviii + 335 págs., EUNED (3da edición); San José.

BUNDSCHUH, J., BIRKLEi, P., FINCH, R.C., DAY, M., ROMERO, J., PANIAGUA, S., ALVARADO, G.E., BHATTACHARYA, B., TIPPMANN, K. \& CHAVES, D., 2007. Geology-related tourism for sustainable development. -En: J. BUNDSCHUH, J. \& ALVARADO, G.E. (eds.): Central America: Geology, Resources and Hazards. Taylor \& Francis, Londres/London. 2: 1015-1098. 
